\title{
Por uma pedagogia dos inocentes
}

\author{
JOSÉ DE SOUZA MARTINS
}

RESUMO: A idéia de uma escola para filhos de "trabalhadores móveis", tema que vem inquietando os países da América do Norte e da Europa, propõe os dilemas da socialização e da educação dos desenraizados em face de uma instituição enraizada, que é a escola. Para conciliar escola com a situação social de quase transumância dos filhos desses trabalhadores, seria necessário reconhecer as funções educativas e socializadoras do próprio aluno, o aluno como professor da diversidade cultural. No fim das contas, admitir uma pedagogia dos inocentes.

m princípio, a pergunta "qual escola para os filhos do trabalhador móvel?" refere-se a um tema que preocupa mais os países ricos do que os países pobres, o que não quer dizer que seja menos relevante em relação a estes últimos. Mais os países que recebem imigrantes estrangeiros do que aqueles em que as migrações são predominantemente internas.

Este texto reflete, necessariamente, minha inserção numa sociedade periférica em que as prioridades temáticas muitas vezes aparecem invertidas em relação às dos países metropolitanos. Mas, creio que a diversidade regional do Brasil e a acentuada importância que em meu país tem hoje as migrações internas de trabalhadores são fundamentais para uma compreensão do tema. Os desencontros de culturas e de visões de mundo situados em momentos polares da história social são de grande relevância para o exame do tema aqui proposto e para sugestões comparativas. Porque, mais do que caracterizar peculiaridades étnicas e culturais, importa compreender os proces-
PALAVRAS-CHAVE: trabalhador móvel, escola, interculturalidade, socialização, educação, identidade social.

Professor do Departamento de Sociologia da FFLCH-USP 
Trabalho apresentado no Seminário sobre "Migrações e futuro", organizado pela revista Migrations et Société e pelo Centre d'Information et d'Études sur Les Migrations Internationales, Paris, 15 a 17 de novembro de 2001. sos sociais que põem o filho do (i)migrante em face de dilemas culturais na constituição de sua identidade. E compreender, também, a continuidade dos valores de referência da sociedade de origem e de seu modo de vida no destino de seus membros ausentes, os filhos pródigos da diáspora moderna.

Talvez por pensar e interpretar a partir do horizonte de uma sociedade que se moderniza tardiamente, em relativo atraso quanto aos países desenvolvidos, encontrei dificuldades para lidar com o conceito de "trabalhador móvel", que em meu país não se usa. "Trabalhador móvel” é ainda um conceito em elaboração, um conceito em busca de sentido e de difícil uso em contextos mais amplos.

Na própria diversidade de situações de trabalho abrangidas por essa concepção, está sugerida a relevância das necessidades de inovação social resultantes da inconstância espacial que lhes é própria. Portanto, creio que o interesse sociológico maior está menos nas formas de expressão cultural do que nas diferenças até significativas de modos de vida entre quem chega a uma sociedade e quem já está nela integrado.

A problemática de interesse sociológico maior, nesse caso, é a precariedade da inserção social dos (i)migrantes nas sociedades de adoção. Estamos, portanto, falando de trabalhador precário de emprego instável, que trabalha e vive temporariamente, ainda que por longo tempo, em país ou região diferente do seu, numa situação social e cultural diversa da sua situação de origem.

O “trabalhador móvel”, nesta proposta, é o trabalhador migrante, estrangeiro ou forasteiro, sujeito a deslocamentos espaciais ocasionais ou mesmo sazonais. De certo modo vai se definindo um mercado de trabalho que não suporta o peso econômico da estabilidade empregatícia do trabalhador e descarta as instituições próprias da realidade social em que essa estabilidade se apóia, do direito ao sindicato, da família à escola. A coisificação da pessoa, própria de uma sociedade em que as relações sociais são mediatizadas pela mercadoria e pelo dinheiro, ganha novas estratégias e novas dimensões e cria, obviamente, novos problemas sociais, tanto para os sujeitos (eventualmente vítimas de situações adversas) quanto para a sociedade (mesmo que deles seus membros não tenham a menor consciência ou não tenham uma consciência individual que coincida com a consciência social e política).

Tendo em conta que muitos desses trabalhadores, tanto os deslocados pelas migrações internacionais quanto pelas migrações internas, fazem da precariedade de seu trabalho uma fonte de ganho adicional em relação aos ganhos possíveis na sociedade e nas regiões de origem, melhor pensá-los como expressão de uma mudança na própria concepção de trabalho.

Nossas referências sociológicas ainda são as de uma época e de uma sociedade em que o trabalho era meio de integração social e de participação. Era o trabalho permanente ou duradouro, na agricultura e mesmo na indústria, base de uma vida de razoáveis certezas, uma vida estável com estabilidade no emprego. Conseqüentemente, uma vida de relações sociais igualmente estáveis, não só no trabalho. 
Quando ainda não se falava em capital social, o trabalhador já era tratado como capital social, coisa que hoje é restrita. O operário ainda era um artesão em muitos setores industriais. Não só conhecedor de um "fazer", mas também conhecedor de um "saber fazer". O desenvolvimento econômico das últimas décadas fragmentou o trabalho ainda mais, exacerbou a divisão social do trabalho, acentuou a separação entre o que se sabe e o que se faz. Esse tipo de trabalhador foi se tornando obsoleto e seu emprego começou a se tornar uma irracionalidade no sistema capitalista.

O trabalhador se tornou plenamente uma peça da máquina de produção. Esse é o trabalho puro, que parece ser uma busca do capitalismo, o trabalho plenamente libertado da pessoa do trabalhador. Essas mudanças indicam, também, mudança na concepção do que é trabalho e do que é trabalhador. O trabalho não foi apenas fragmentado pela divisão social do trabalho e pelas especializações. Ele foi agrupado em setores relativamente autônomos, uma autonomia relativa de fragmentos de um processo de trabalho que há algumas décadas era um processo unitário, no interior de uma mesma empresa e, não raro, de um mesmo espaço.

Hoje, em consequiência, é necessário pressupor uma ecologia do trabalho e o conhecimento das condições dessa multiespacialidade do trabalho que acaba impondo ao trabalhador a condição de trabalhador móvel, uma espécie de nômade do trabalho. No cume desse processo está o trabalho nômade, o trabalho que muda de lugar e leva consigo seus operários. É o caso da construção civil: a empresa existe onde existe o trabalho; não é o trabalho que existe onde existe a empresa. São, portanto, duas situações diversas de trabalho móvel. Para o trabalhador cuja residência também se torna temporária, a mobilidade e a instabilidade se estende à sua família, nos casos em que ele se faz acompanhar por ela. Uma instabilidade que se estende, também, às relações sociais dessa família.

A preocupação com filhos de "trabalhadores móveis" parece sugerir interesse pela escola como instituição, como lugar e programa de ensino, como referência institucional estável num mundo de situações sociais instáveis. Não seria, por isso, a escola para "trabalhadores móveis" uma escola de confinamento cultural e pedagógico? A literatura parece trabalhar com o pressuposto, difundido entre os próprios (i)migrantes, da escola imóvel para os filhos dos (i)migrantes, uma escola assimilacionista (cf. Dubreuil, 2001). Porém, num mundo marcado por crescente mobilidade espacial, o que fazer com uma escola da imobilidade espacial que é ao mesmo tempo a escola da ascensão social (e, portanto, da mobilidade social)?

O migrante (e o imigrante, sobretudo) defronta-se, pois, nas sociedades de destino com instituições territorializadas, não só as estatais, como a escola, mas no geral também outras como o sindicato e a igreja. As grandes mediações dos valores sociais e dos direitos sociais são mediações desse tipo. As relações sociais do (i)migrante são construídas através de instituições e organizações orientadas por valores da estabilidade espacial, da permanência e não do deslocamento. 
Vivemos num mundo em que o trabalhador está sendo desterritorializado e, num certo sentido, o próprio trabalho o está. A mobilidade das empresas que se deslocam em conformidade com interesses e estímulos financeiros, de um país para outro e de uma região para outra, indica que o trabalho também está sendo desterritorializado.

Convém considerar que nem todos os (i)migrantes dessa nova realidade do trabalho são pobres. Ao contrário, não raro são relativamente jovens, são profissionalmente qualificados e até ganham bem. Dado que migram na expectativa de retorno à sociedade de origem ou à região de origem, evitam enraizamentos, mesmo em relação ao que seriam os direitos fundamentais do próprio trabalhador. Aceitam condições adversas de trabalho e de vida em sociedades que se aproveitam de seu desenraizamento e, até, de sua clandestinidade. Com base no trabalho desterritorializado vai se constituindo a categoria do não-cidadão, pois cidadão é uma categoria territorial. $O$ cidadão de um país, quando emigra, não leva consigo a sua cidadania, quando muito leva resquícios dela.

As instituições da sociedade moderna, que é a sociedade da mobilidade, mediada pela dinâmica do mercado, são, contraditoriamente, instituições que pressupõem o enraizamento territorial e a falta de mobilidade. Todo ser humano que se move ainda parece uma anomalia. As instituições não estão preparadas para recebê-lo nem para apoiá-lo, apesar de muitos esforços nesse sentido. Isso vale tanto para a escola quanto para o sindicato quanto para a Igreja, quanto, certamente, para outras instituições fundamentais.

Refletir sobre a educação e a escola tomando como referência alguém que está "fora do lugar" é um desses desafios próprios de uma situação social que pede uma ação transformadora. Mas, pede-a não a partir do marco da ordem, e sim a partir do que até aqui a sociedade tem considerado desordem: a instabilidade espacial do trabalhador. A própria educação foi sempre pensada como educação para a ordem, ou educação para a mudança no marco da ordem: o progresso no marco da ordem e o progresso como decorrência da ordem.

Além disso, tem sido regra que a escola reflita o modo de ser e de pensar das sociedades dominantes e, nelas, das classes dominantes, daqueles que já têm um lugar definido na (naquela) sociedade. Esta discussão, porém, pede que se pense a escola do ponto de vista dos "sem-lugar", dos desenraizados, dos que transitam, dos que buscam uma sociedade e não dos que são de uma sociedade.

Talvez por isso seja fundamental pensar o desafio a partir, também, das experiências sociais de educação em sociedades que ficam na margem da sociedade que se habituou a pensar a educação do ponto de vista de sua centralidade e não de sua marginalidade. As carências próprias das sociedades periféricas gerou estratégias de sobrevivência cultural. Como gerou, também, uma pedagogia popular que a assegura, que define o que se poderia chamar de escola da margem. Refiro-me às ações educacionais populares e espontâneas que permitem transmitir de uma geração a outra o conhecimento 
indispensável a que um modo de ser e uma certa visão de mundo se mantenham e possam ser legados à geração seguinte ${ }^{1}$.

Mas, a sociedade de adoção, a sociedade nova para o (i)migrante, é também a sociedade das incógnitas, dos desafios de conhecimento, da inutilidade de certos conhecimentos prévios: de que serve na cidade todo o conhecimento do cultivo do café que foi aprendido no campo? De nada serve. Mas, certamente serve, e muito, o modo de preparar o café, sobretudo porque se trata, em muitos lugares, de uma bebida própria dos ritos de sociabilidade e de aproximação social.

Um tema correlato é o tema da memória. As sociedades ocidentais incluem, em suas técnicas de socialização do estrangeiro e do forasteiro, meios para promover o esquecimento cultural e social. A socialização formalizada na educação das sociedades de adoção tem sido, também, uma técnica de ocultamento do passado e dos antepassados. Mesmo na periferia, como no caso do Brasil, no mundo da margem em relação aos países dominantes, os antigos países metropolitanos, isso sempre esteve presente nas técnicas usadas pelos missionários para converter os índios.

Mas, essas técnicas criaram o duplo e a cultura do duplo - o candomblé se acoplou ao catolicismo da Contra-reforma; mais do que sincretismo, produziu ocultamento e dissimulação. A memória acaba sobrevivendo como referência clandestina, como clandestina continuidade de um passado que a nova realidade procura apagar.

É a partir desses resíduos ocultos que o imigrante pode rememorar, recriar e inventar cultural e socialmente, novas concepções e novas relações. As associações de mútuo socorro, no Brasil, disseminadas pelos imigrantes europeus após o fim da escravidão, no século XIX, recriaram a comunidade que se deixou para trás. Era comunidade, mas era uma outra comunidade. Era modo comunitário de resolver problemas, de reconstruir a sociabilidade. Mas, não era a mesma comunidade, a comunidade da memória. Era diverso o modo da comunidade ser revivida no presente da sociedade de adoção.

Pensar a escola dos transumantes, dos sem destino, é pensar em combater essa clandestinidade da memória. Porque a escola enraizada, a escola da estabilidade situacional, pela qual a sociedade de adoção se propõe ao (i)migrante, ao não conhecer a legitimidade e a relevância da cultura de origem do estrangeiro e do forasteiro, fecha-se sobre si mesma. Ao mesmo tempo, deixa um resíduo de ação educativa que é aquilo que ela não pode assimilar, nem conhecer, nem reconhecer. Esse resíduo é a cultura da sociedade de origem, a sociabilidade internalizada sobretudo na primeira socialização do (i)migrante. Cria-se, assim, o duplo e a duplicidade das orientações culturais do (i)migrante e de seus descendentes. Essa é a base da criatividade do seu ajustamento na sociedade de adoção, um ajustamento auto-afirmativo e de afirmação da (sua) diferença.

Há uma implicação na proposta de uma escola para os filhos dos "trabalhadores móveis": o risco da destruição das bases da inventividade so-
1 Sobre esse tema, é ilustrativa a extensa bibliografia de Carlos Rodrigues Brandão. Cf., em especial, Brandão (1983; 1984 e 1990). 
cial que o ocultamento da memória social e da cultura de origem propõe, que a práxis autodefensiva sugere a todo momento. A existência de uma escola para os "trabalhadores móveis", isto é, a formalização escolar da diferença, não destruiria a conflitividade criativa dessa situação, o autodefensivo do segredo e do ocultamento? Não se estaria institucionalizando (e capturando) a diferença e trazendo-a para o universo do poder e do controle social de que a escola, no fundo, é um instrumento?

Ao mesmo tempo, essa dúvida propõe outra. Manter em âmbitos separados, de um lado, a cultura e os modos de ser da sociedade de origem, de certa maneira confinados na vida privada e doméstica, e, de outro, a escola enquanto agência da cultura e da sociedade de adoção, certamente dificultaria a interculturalidade que há nos valores da solidariedade, da integração na diferença que dela se espera numa perspectiva humanística.

Para enfrentar essas dificuldades, é preciso saber que sociedade o (i)migrante carrega consigo, qual é sua sociedade de referência e qual é sua disposição para abrir mão dela e assimilar a sociedade de adoção. Resta saber que motivos pode ter o migrante para manter apego à sociedade de origem e com ela continuar a se identificar. Sobretudo, convém ter em conta em que medida retornar é parte do projeto do (i)migrante. É preciso saber, também, qual é o legado dessas referências aos filhos, em que medida os pais não se importam de se tornar estrangeiros em face dos filhos assimilados, certamente através da escola. Qual a função da sociedade de adoção no retorno e na regeneração da sociedade de origem? Ser unicamente fonte dos ganhos do trabalho?

Por outro lado, é preciso saber que motivos podem ter os setores que se interessam pelos (i)migrantes para preservação de sua cultura e de sua identidade. Preservar para que, afinal? A relativa ansiedade que acompanha (i)migrantes em sociedades ricas, originários de sociedades pobres, para assimilar língua, falas, modos, etc., parece indicar que há alguma dose de desapreço pelas próprias tradições e pelos próprios modos de ser herdados da sociedade de origem. Esse "estado" é compreensível, sobretudo em sociedades hostis e agressivas em relação a estrangeiros e forasteiros, particularmente entre os da classe média, já de certo modo desenraizados por sua origem social, abertos para o que é médio e, portanto, para o que não tem identidade.

Nessa perspectiva, pensar a escola em sociedades de encontro de portadores de tradições culturais desencontradas não é uma coisa simples. Não se trata apenas de impor um ato de vontade política e pedagógica para assegurar que a convivência e a interação intercultural se realize. Nem cabe pensar o (i)migrante como vítima de uma convivência adversa. Dificuldades há sempre dos dois lados.

Nos últimos trinta anos, no Brasil, povos tribais alcançados pela nova onda de ocupação capitalista do território, pela chegada a suas terras do branco inescrupuloso ávido de lucro, manifestaram, depois de um período inicial de tensão e conflito, interesse pelo conhecimento da cultura do adventício, poderoso e, geralmente, rico. Essa é uma situação inversa à dos países 
europeus, dos Estados Unidos e do Canadá. Queriam compreender como funciona a cabeça do branco que invade suas terras e tenta dominá-lo. Assimilaram rapidamente a escola como meio de acesso a essa informação vital para defesa de sua cultura e de seu modo de vida.

Portanto, a escolarização é concebida aí como um meio de ter algum domínio e alguma compreensão sobre a diversidade cultural e social. Um meio para poder administrar autodefensivamente a competência destrutiva do adventício poderoso e sua cultura. Nesse sentido, fica evidente algo que quase todos nós temos dificuldade para entender: a escola, tal como a concebemos, é uma instituição própria da cultura da sociedade de adoção, e do poder que ela representa, e não instituição neutra em que possam conviver concepções até antagônicas do que é ensinar e aprender.

A escola institucional e formal é, assim, destinada não só aos enraizados, mas também àqueles que se espera enraizar. Se falamos em "escola" temos que pensar nessa dificuldade. Se falamos em "educação", podemos, então, alargar a problemática e sua compreensão. Porque podemos falar na informalidade da educação que é parte do processo de socialização, sobretudo, socialização secundária das novas gerações.

Em meu país, a escola convencional não tem qualquer compromisso com as tradições culturais das classes subalternas, das pessoas simples. Sobretudo, não o tem com as populações de origem rural, expulsas do campo pelas grandes transformações que têm ocorrido na agricultura. São, no geral, pessoas portadoras de uma cultura comunitária e camponesa, profundamente marcada por mediações religiosas do catolicismo tradicional dos tempos da Conquista. Não raro, cultura criada pelos missionários no sentido de conciliar as tradições indígenas, dos povos conquistados, com as concepções religiosas do catolicismo da Contra-reforma. Criou-se aí um catolicismo popular revestido por formas culturais indígenas. Há no mundo urbano brasileiro, lugar de destino desses migrantes, um grande desapreço por essa cultura ancestral, desapreço que aparece na sua folclorização e até mesmo na sua ridicularização.

A hostilidade cultural da instituição escolar a essas tradições, fortíssimas ainda nas populações urbanas de origem rural e mesmo nas populações que permanecem no campo, não chegou a destruí-las porque as próprias populações tradicionais desenvolveram vários mecanismos pedagógicos para transferir às novas gerações o seu saber. Isso não quer dizer que a cultura tradicional não esteja ameaçada ${ }^{2}$. Quer dizer apenas que ela tem agentes sociais de defesa e autoproteção, por meio de sua transferência seletiva a membros das novas gerações.

Por tudo isso, uma escola para os filhos dos trabalhadores móveis pode estar sugerindo uma escola excludente, um agravamento da exclusão social. Mesmo que se imagine essa escola como escola da interculturalidade. Talvez se possa pensar numa escola em diálogo com a diversidade social e cultural da população circundante. Não uma escola do poder e sim uma escola da sociedade real, a sociedade da diversidade, da diferença.
${ }^{2}$ Como na França e em outros lugares, também no Brasil a escola é de modo geral avessa à função de mediação cultural na relação entre residentes e adventícios. Sobre a França, cf. Lorcerie (1996). 
Nessa perspectiva, porém, é necessário admitir que a educação deve comportar uma pedagogia em que o aluno é também o educador. Basicamente, ele é o conhecedor dos códigos e padrões culturais da sociedade de origem. Ou, ao menos, é ele que tem o vínculo privilegiado de viver no limite com os depositários do saber da sociedade de origem, que são os membros de sua família.

Estamos falando, pois, mais propriamente em uma dimensão da socialização das novas gerações que envolve a simultânea ressocialização das gerações adultas encarregadas pela sociedade de adoção de realizar a tarefa pedagógica de educar os (i)migrantes. Inverto aqui uma constatação de um grande sociólogo de meu país. Estudando grupos infantis informais em bairros de imigrantes estrangeiros da cidade de São Paulo, descobriu que as crianças tinham um importante papel na ressocialização de seus pais para a sociedade de adoção ${ }^{3}$.

Esse tema, certamente, envolve questões políticas, sobretudo pela crítica implícita às instituições da ordem. Há um certo risco de que a proposta de uma escola para os filhos de "trabalhadores móveis" corresponda ao temor do conflito que a cultura residual dos (i)migrantes possa acarretar. Portanto, além de nos perguntarmos "qual escola para os filhos dos 'trabalhadores móveis'?”, deveríamos, igualmente, fazer indagações a respeito de quais são as condições sociais e políticas para se pensar numa escola da interculturalidade.

Convém lembrar que "trabalhadores móveis" não são cidadãos dos países em que trabalham. Raramente têm direitos. Não raro são clandestinos ou tendem à clandestinidade. Não votam. Não constituem massa de pressão política e de reivindicação social. Vivem num mundo de silêncio político compulsório. Significa que devam viver, também, num mundo de silêncio cultural ou educacional? Há condições de quebrar esse silêncio? Tem acontecido? Uma escola para os filhos dos "trabalhadores móveis" é sem dúvida uma proposta de quebra desse silêncio, ou dessa fala cultural intramuros, circunscrita ao âmbito do privado ou dos "guetos" culturais que (i)migrantes muitas vezes tendem a formar.

Antes de passar pela questão propriamente pedagógica e institucional (qual escola?) as sociedades que se inquietam democratica e positivamente com a necessidade de fazer da escola um instrumento da interculturalidade precisariam traduzir essa inquietação em ações afirmativas de diálogo cultural. Nesse sentido, mais do que a escola (e o poder que a rege), o que parece vir antes é a sociedade civil enquanto fonte de reconhecimento da legitimidade da diferença social e cultural das origens nacionais ou regionais. Os próprios protagonistas da convivência espacial de culturas é que podem, mais do que ninguém, erguer os andaimes para a construção social da realidade dessa convivência.

Se a saída está nos setores da sociedade civil sensíveis, estamos falando mais em cumplicidade do que em direitos. Nesse caso, estamos falando em movimento social. Nas sociedades de adoção, o caminho seria que es- 
ses setores se mobilizassem no sentido de quebrar as regras e de oferecer aos filhos desses trabalhadores o equivalente não escolar da escola de que precisam, a da interculturalidade e do acolhimento. Ao menos como um primeiro momento, como momento de criar o lugar da escola "móvel" em lugar da escola dos "imóveis". E nesse sentido, sublinhar mais que o poder socializador da escola, o poder socializador do aluno, tanto do que vem de longe quanto do que já está lá. Sublinhar e reconhecer a grande dimensão humanística dessa espécie de pedagogia dos inocentes.

Estamos, em grande medida, falando numa educação "sem escola" ou numa escola adjetiva em relação ao processo formal de educar. A escola formal e enraizada num certo sentido é adversa às possibilidades educacionais dos transumantes, porque não assume nem pode assumir seus valores, seus objetivos, o tipo de ser humano que procuram ser. A escola formal não é "inimiga" da cultura dos adventícios. Mas, lhe é indiferente.

Recebido para publicação em agosto/2001
MARTINS, José de Souza. Towards a pedagogy of the innocents. Tempo Social; Rev. Sociol. USP, S. Paulo, 13(2): 21-30, November 2001.
ABSTRACT: The idea of a school for the children of migrant workers, an issue that has been of concern in the countries of North America and Europe, proposes the dilemmas of socialization and education of those uprooted in face of a rooted institution such as the school. To conciliate the school with the social situation of quasi transhumance of these workers' children it would be necessary to recognize the educational and socializing functions of the students themselves, the student as teacher of cultural diversity. In other words, to admit a pedagogy of the innocents.

\section{REFERÊNCIAS BIBLIOGRÁFICAS}

Brandão, Carlos Rodrigues. (1983) Casa de escola. Campinas, Papirus. . (1984) Saber e ensinar. Campinas, Papirus. . (1990) O trabalho de saber (Cultura camponesa e trabalho rural). São Paulo, FTD.

DubreuIL, Bertrand. (2001) Inmigration et stratégies familiales en milieu scolaire. Migrations et Société, Paris, XIII(76): 77-79, mai-août.
KEY WORDS: migrant workers, school, interculturality, socialization, education, social identity. 
FERnANDES, Florestan. (1961) Folclore e mudança social na cidade de São Paulo. São Paulo, Editora Anhembi.

LORCERIE, Françoise. (1996) L'école, lieu de médiation culturelle. Migrations et Société, Paris, VIII(46-47): 29-41, juillet-octobre. 